\title{
EDITORIAL
}

\section{Bronchodilator reversibility in COPD: the roguish but harmless little brother of airway hyperresponsiveness?}

\author{
E.F. Hansen* and J. Vestbo*,\#
}

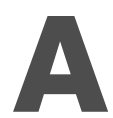
irway hyperresponsiveness (AHR) in chronic obstructive pulmonary disease (COPD) is well described in an epidemiological context with rather consistent results. It is known that AHR is a negative prognostic marker, associated with an accelerated decline in forced expiratory volume in one second (FEV1) [1-3] and probably also associated with an increase in mortality [4]. The presence of AHR in individual subjects is almost constant. Thus, in the Lung Health Study (LHS), where responsiveness to methacholine was measured at two time points 5 -yrs apart, $<17 \%$ of the participants changed responsiveness by $\geqslant 2$ concentrations [5]. Smoking cessation is reported to have a beneficial effect on AHR [5], and smokers with high levels of AHR seem to gain more from smoking cessation in terms of FEV1 [6].

Even if a lot of the "hows" for AHR in COPD are known, the "whys" have still not been answered. It is not known if AHR truly denotes a susceptibility to smoking, in line with the Dutch hypothesis, or if it is a mere reflection of the progression in COPD. AHR is, unlike in the case of asthma, resistant to current treatments, and extremely little is known of the underlying airway biology associated with AHR in COPD.

Bronchodilator reversibility (BDR) in COPD has also been extensively studied, but with more complex and confusing results than for AHR. One of the key problems when examining BDR is that it is not a constant feature in the individual patient. The large within-subject variability of BDR has been shown in moderate-to-severe COPD, where $\sim 50 \%$ of the patients changed responder status between study visits [7], and it is also noted in subjects with mild COPD, as seen in the study by ANTHONISEN et al. [8] in the current issue of the European Respiratory Journal.

There has been much interest in the possible association between BDR and prognosis in COPD, but, despite quite a few studies, a clear picture has not been elucidated. Some studies have found reversibility to be a marker of an unfavourable prognosis in terms of FEV1 decline [1,9], while others have found the opposite $[2,10]$. In terms of mortality, one study has shown a favourable effect of BDR [11], whereas others have found no effect of BDR on mortality [10, 12]. BDR can be expressed in different terms: for example as an absolute value;

*Dept of Cardiology and Respiratory Medicine, Hvidovre Hospital, Copenhagen, Denmark. \#North West Lung Centre, Wythenshawe Hospital, Manchester, UK.

CORRESPONDENCE: E.F. Hansen, Dept of Cardiology and Respiratory Medicine 253, Hvidovre Hospital, DK-2650 Hvidovre, Denmark. Fax: 45 36323755. E-mail: Frausing@dadlnet.dk relative to baseline FEV1; relative to predicted FEV1; or in even more sophisticated ways. The 3-4-fold increase in statistical models due to this has often brought more confusion than clarity.

The data set from the LHS is unique in respect to sample size, as well as length of follow-up, and it is unlikely, in the foreseeable future, that the picture of BDR in mild COPD will be developed much further than the one presented by ANTHONISEN et al. [8] in this issue of the Journal. ANTHONISEN et al. [8] followed 4,194 subjects with mild COPD for 11 yrs, with reversibility testing each year for the first $5 \mathrm{yrs}$, and again 6 yrs later. Furthermore, AHR with methacholine was measured at baseline, and smoking status throughout the 11 yrs of follow-up was recorded. Thus, it has been possible to examine the effect of BDR on prognosis in terms of FEV1 decline, to examine the change with time in BDR, and to examine the association between changes in BDR, changes in smoking habits and baseline AHR.

The main conclusions from the study seem straightforward. ANTHONISEN et al. [8] found that baseline bronchodilator response did not relate to the subsequent decline in lung function, assessed by data on postbronchodilator FEV1 from 1 to 11 yrs. This observation is in accordance with data from the Inhaled Steroids in Obstructive Lung Disease in Europe (ISOLDE) study [7], but not with data from the Intermittent Positive Pressure Breathing (IPPB) trial [10]. Compared to the latter study, the LHS had more patients, a substantially longer follow-up and a more appropriate study design in respect to examining the effect of bronchodilator responses on prognosis. A striking finding in the LHS study was the marked increase in bronchodilator reversibility during the 1st yr of follow-up. The increase was observed in all smoking strata, but was much larger in the group of sustained quitters than in intermittent quitters and continuous smokers. A cross-sectional association between smoking and bronchodilator response has previously been reported [10] and it can be speculated that smoking cessation, by reducing airway inflammation, mediates a "potential for bronchodilatation". The actual reversibility was not large, the mean reversibility being $111 \mathrm{~mL}$, equivalent to $4.3 \%$ of baseline FEV1. Thus, it is possible that the findings from the LHS do not apply to patients with more advanced or reversible disease, such as those entered in some of the large medication trials, where the mean relative reversibility has been in the order of $20 \%$ [13].

A more thorough examination of the reversibility data from LHS reveals that more confusion remains. If it is assumed that 
AHR and BDR reflect the same underlying airway abnormality, it is difficult to put the pieces together. BDR and AHR were positively correlated, as would be expected. However, smoking cessation reduced the level of AHR [5], whereas it increased the level of BDR in the same population. BDR declined with age, whereas the opposite was the case for AHR [5]. Disease progression increased both AHR and BDR, judged from data in continuing smokers. Finally, the baseline level of AHR was a strong predictor of subsequent decline in FEV1. As mentioned, this was not the case for BDR.

So can we make any sense from the above conclusions on bronchodilator reversibility in chronic obstructive pulmonary disease? On some issues a clearer picture emerges. It seems that we now can discard bronchodilator reversibility as a prognostic factor in chronic obstructive pulmonary disease. If postbronchodilator forced expiratory volume in one second is controlled for there is no convincing evidence that the level of reversibility per se is associated with the subsequent decline in lung function or with mortality. In fact, we now have convincing evidence that the level of reversibility is not important for prognosis in chronic obstructive pulmonary disease, and this statement seems to be true regardless of the level of disease severity. On the different "behaviour" of airway hyperresponsiveness and bronchodilator reversibility in chronic obstructive pulmonary disease, it can be concluded that they have something in common, but perhaps more that separates them. They may very well be brothers; however, as airway hyperresponsiveness grows up and shows its bad character, bronchodilator reversibility still plays around with us and we should probably not take him too seriously.

\section{REFERENCES}

1 Campbell AH, Barter CE, O'Connell JM, Huggins R. Factors affecting the decline of ventilatory function in chronic bronchitis. Thorax 1985; 40: 741-748.

2 Postma DS, De Vries K, Koëter GH, Sluiter HJ. Independent influence of reversibility of airflow obstruction and non-specific hyperreactivity on the long-term course of lung function in chronic airflow obstruction. Am Rev Respir Dis 1986; 134: 276-280.

3 Tashkin DP, Altose MD, Connett JE, Kanner RE, Lee WW, Wise RA, for the Lung Health Study Research Group.
Methacholine reactivity predicts changes in lung function over time in smokers with early chronic obstructive pulmonary disease. Am J Respir Crit Care Med 1996; 153: 1802-1811.

4 Hospers JJ, Postma DS, Rijcken B, Weiss ST, Schouten JP. Histamine airway hyper-responsiveness and mortality from chronic obstructive pulmonary disease: a cohort study. Lancet 2000; 356: 1313-1317.

5 Wise RA, Kanner RE, Lindgren $\mathrm{P}$, et al. The effect of smoking intervention and an inhaled bronchodilator on airways reactivity in COPD. Chest 2003; 124: 449-458.

6 Scanlon PD, Connett JE, Waller LA, et al. Smoking cessation and lung function in mild-to-moderate chronic obstructive pulmonary disease. Am J Respir Crit Care Med 2000; 161: 381-390.

7 Calverley PMA, Burge PS, Spencer S, Anderson JA, Jones PW, for the ISOLDE Study Investigators. Bronchodilator reversibility testing in chronic obstructive pulmonary disease. Thorax 2003; 58: 659-664.

8 Anthonisen NR, Lindgren PG, Tashkin DP, Kanner RE, Scanlon PD, Connett JE, for the Lung Health Study Research Group. Bronchodilator response in the Lung Health Study over 11 years. Eur Respir J 2005; 26: 45-51.

9 Kanner RE. The relationship between airways responsiveness and chronic airflow limitation. Chest 1984; 86: 54-57.

10 Anthonisen NR, Wright EC, Hodgkin JE. Prognosis in chronic obstructive pulmonary disease. Am Rev Respir Dis 1986; 133: 14-20.

11 Postma DS, Gimeno F, van der Weele LT, Sluiter HJ. Assessment of ventilatory variables in survival prediction of patients with chronic airflow obstruction: the importance of reversibility. Eur J Respir Dis 1985; 67: 360-368.

12 Hansen EF, Phanareth K, Laursen LC, Kok-Jensen A, Dirksen A. Reversible and irreversible airflow obstruction as predictor of overall mortality in asthma and chronic obstructive pulmonary disease. Am J Respir Crit Care Med 1999; 159: 1267-1271.

13 Mahler DA, Wire P, Horstman D, et al. Effectiveness of fluticasone propionate and salmeterol combination delivered via the diskus device in the treatment of chronic obstructive pulmonary disease. Am J Respir Crit Care Med 2002; 166: 1084-1091. 